\title{
Pulmonary valve replacement in repaired tetralogy of Fallot: Determinants of early postoperative adverse outcomes
}

\author{
Laura Dos, MD, ${ }^{\mathrm{a}, \mathrm{c}}$ Alexander Dadashev, MD, ${ }^{\mathrm{a}}$ David Tanous, MBBS, ${ }^{\mathrm{a}}$ Ignacio J. Ferreira-González, MD, ${ }^{\mathrm{d}}$ \\ Kim Haberer, ${ }^{a}$ Samuel C. Siu, MD, ${ }^{a}$ Glen S. Van Arsdell, MD, ${ }^{b}$ Erwin N. Oechslin, MD, ${ }^{a}$ \\ William G. Williams, MD, ${ }^{b}$ and Candice K. Silversides, MD $^{\mathrm{a}}$
}

Objective: We sought to examine the frequency of early postoperative complications and preoperative predictors of prolonged hospitalization in adults with repaired tetralogy of Fallot undergoing pulmonary valve replacement.

\begin{abstract}
Methods: This was a retrospective study of consecutive adult patients undergoing surgical intervention between 1995 and 2006. A multivariate logistic regression model was used to identify determinants of prolonged hospi-
\end{abstract} talization.

\begin{abstract}
Results: One hundred sixteen patients (mean age, $36 \pm 11$ years) underwent 118 pulmonary valve replacements. Most $(95 \%)$ operations included additional procedures, such as pulmonary artery/outflow tract reconstruction or tricuspid valve annuloplasty. The early postoperative mortality ( $<30$ days) was $2.5 \%$. The majority of the patients $(60 \%)$ had no postoperative complications. The postoperative adverse events included postoperative arrhythmias $(19 \%)$, respiratory complications $(13 \%)$, reoperation during admission $(13 \%)$, renal dysfunction $(13 \%)$, and myocardial infarction (3\%). Postoperative adverse events were associated with prolonged hospitalization (14 \pm 12 vs $7 \pm 3$ days, $P=.001$ ). In the multivariate analysis age at reoperation of greater than 45 years (odds ratio, $6.1 ; 95 \%$ confidence interval, 1.6-23.6; $P=.009$ ), the number of previous sternotomies (odds ratio, 3.8; 95\% confidence interval, 1.4-10; $P=.007$ ), and the need for urgent surgical intervention (odds ratio, $5.7 ; 95 \%$ confidence interval, 1.1-27.8; $P=.03$ ) were predictors of prolonged hospitalization.
\end{abstract}

Conclusion: Pulmonary valve replacement in adults with repaired tetralogy of Fallot has a low mortality risk. The most common early postoperative complications are arrhythmias and respiratory and renal complications. Although most early postoperative complications do not result in long-term sequelae, they are associated with prolonged hospitalization. Patients undergoing urgent interventions, older patients, and those with multiple previous sternotomies are at the highest risk for prolonged hospitalization.

Earn CME credits at

http://cme.ctsnetjournals.org

Tetralogy of Fallot (TOF) is one of the most common forms of cyanotic congenital heart disease. Intracardiac repair, performed primarily in childhood, has been performed for more than 50 years, and the current early mortality rate is low. ${ }^{1,2}$

\footnotetext{
From the Toronto Congenital Cardiac Center for Adults, ${ }^{\text {a }}$ Toronto General Hospital/ University Health Network, Toronto, Ontario, Canada; the Hospital for Sick Children, ${ }^{\mathrm{b}}$ Toronto, Ontario, Canada; Unitat de Cardiopaties Congènites de l'Adolescent I de l'Adult (UCCAA), ${ }^{\mathrm{c}}$ Àrea del Cor, Hospital de la Vall d'Hebron, Barcelona, Spain; and the CIBER de Epidemiología y Salud Pública (CIBERESP)-Unitat d'Epidemiologia, Servei de Cardiologia, ${ }^{\mathrm{d}}$ Hospital de la Vall d'Hebron, Barcelona, Spain.

Received for publication June 14, 2008; revisions received Jan 5, 2009; accepted for publication Feb 25, 2009; available ahead of print May 11, 2009.

Address for reprints: Laura Dos, MD, Unitat de Cardiopaties Congènites de l'Adolescent i de l'Adult (UCCAA), Àrea del Cor, Hospital Universitari Materno-Infantil Vall d'Hebron, Avinguda de la Vall d'Hebron 119-129, 08035-Barcelona, Spain (E-mail: laura_dos_subira@hotmail.com).

J Thorac Cardiovasc Surg 2009;138:553-9

$0022-5223 / \$ 36.00$

Copyright $(c) 2009$ by The American Association for Thoracic Surgery

doi:10.1016/j.jtcvs.2009.02.042
}

After repair, pulmonary regurgitation is common, but complications usually do not occur until adulthood. There is increasing need for pulmonary valve replacement (PVR) in the adult late after TOF repair. ${ }^{3,4}$ Although the use of percutaneous techniques is emerging for a selected group of patients, ${ }^{5,6}$ the current treatment for pulmonary regurgitation continues to be surgical for the majority of patients.

Postoperative adverse outcomes and risk factors for these events have been well defined in adults with acquired heart disease undergoing cardiac surgery, ${ }^{7-9}$ but these large studies have typically not included adult patients with congenital heart defects. The limited data on reoperations in adult patients with congenital heart disease come from studies with small number of patients and mixed diagnoses. ${ }^{10-13}$ With the growing population of patients surviving with TOF and requiring PVR, a detailed examine of the postoperative complications and length of stay ${ }^{14-16}$ is important to identify the high-risk patients and develop strategies to improve outcomes. The primary objectives of this study were (1) to determine the frequency of postoperative adverse events (PAEs) after PVR in adults with repaired TOF and (2) to identify preoperative factors associated with both PAEs and prolonged postoperative length of stay (PLOS). 


$$
\begin{aligned}
& \text { Abbreviations and Acronyms } \\
& \begin{aligned}
\text { CI } & =\text { confidence interval } \\
\text { OR } & =\text { odds ratio } \\
\text { PAE } & =\text { postoperative adverse event } \\
\text { PLOS } & =\text { postoperative length of stay } \\
\text { PVR } & =\text { pulmonary valve replacement } \\
\text { RVOT } & =\text { right ventricular outflow tract } \\
\text { TOF } & =\text { tetralogy of Fallot }
\end{aligned}
\end{aligned}
$$

\section{MATERIALS AND METHODS}

After approval by the institutional research ethics board, 136 consecutive adult patients ( $>18$ years) who underwent late reoperations ( $>1$ year) after intracardiac repair of TOF between May 1995 and October 2006 were identified by using a prospectively maintained cardiovascular surgery database (Cardiovascular Surgery Database, gwillms@istar.ca) at SickKids (Toronto, Canada). Patients with pulmonary atresia were not included because of the potentially different surgical risk profile of this population, including the size and distribution of the pulmonary arteries. Among the remaining cases, 116 patients undergoing 118 PVRs were identified (One of the patients required a redo PVR 5 years after the initial operation because of endocarditis, and another patient required redo PVR and tricuspid annuloplasty 8 years after the initial operation because of valve degeneration.) Demographic data, clinical information, and surgical details were obtained from the patient's records. Data abstraction also included preoperative blood work, results of preoperative electrocardiographic analysis, echocardiographic analysis, cardiopulmonary testing, and cardiac magnetic resonance imaging studies when available.

PAEs included death, need for reoperation, stroke, myocardial infarction, renal failure, respiratory complications, and postoperative arrhythmias (see the Appendix for definitions). ${ }^{14,17}$

Results are presented as the mean and standard deviation for continuous variables with normal distribution and as the median and interquartile range for variables with nonnormal distribution. Comparisons of variables were made by using the Student's $t$ test, the $\chi^{2}$ test, or the Fisher's exact test, as appropriate. Preoperative determinants of prolonged PLOS were identified by using a multivariate logistic regression model. Variables were entered in the model based on their clinical plausibility and significant association with the primary end point in the univariate model $(<0.10)$.

\section{RESULTS}

Baseline characteristics of the 116 patients (undergoing 118 procedures) are presented in Table 1 . The majority of patients $(58 \%)$ had initial palliative procedures, including Blalock-Taussig shunts $(51 \%)$, Potts shunts $(2 \%)$, Waterston shunts $(4 \%)$, or closed Brock valvotomies $(3 \%)$. The mean age at the time of the first palliative procedure was 3 \pm 3 years (median, 1.9 years; interquartile range, $1-4$ years), and the mean age at the time of intracardiac repair was $9 \pm 6$ years (median, 7 years; interquartile range, $5-10$ years), with

\begin{tabular}{|c|c|}
\hline Variable & \\
\hline \multicolumn{2}{|l|}{ Clinical } \\
\hline Age (y) & $36 \pm 11$ \\
\hline Sex (female) & $57(48 \%)$ \\
\hline Body surface area $\left(\mathrm{m}^{2}\right)$ & $1.8 \pm 0.24$ \\
\hline Body mass index $\left(\mathrm{kg} / \mathrm{m}^{2}\right)$ & $26 \pm 5$ \\
\hline Any cardiac medication & $56(47 \%)$ \\
\hline Diabetes & $5(4 \%)$ \\
\hline Hypertension & $4(3 \%)$ \\
\hline Dyslipidemia & $14(12 \%)$ \\
\hline Smoker & $24(20 \%)$ \\
\hline No. of previous sternotomies & $1.2 \pm 0.5$ \\
\hline History of arrhythmia & $52(44 \%)$ \\
\hline Supraventricular & $35(30 \%)$ \\
\hline Ventricular & $23(19 \%)$ \\
\hline Admission for $\mathrm{CHF}$ & $15(13 \%)$ \\
\hline NYHA functional class $>2$ & $23(20 \%)$ \\
\hline History of syncope & $18(15 \%)$ \\
\hline Baseline oxygen saturation (\%) & $97 \pm 3$ \\
\hline Right aortic arch & $30(25 \%)$ \\
\hline \multicolumn{2}{|l|}{ Laboratory values } \\
\hline Glomerular filtration rate $(\mathrm{mL} / \mathrm{min})$ & $110 \pm 38$ \\
\hline Creatinine $(\mu \mathrm{mol} / \mathrm{L})$ & $82 \pm 25$ \\
\hline \multicolumn{2}{|l|}{ Electrocardiographic values } \\
\hline Sinus rhythm & $106(90 \%)$ \\
\hline QRS duration (ms) & $170 \pm 24$ \\
\hline QRS $>180 \mathrm{~ms}$ & $49(42 \%)$ \\
\hline \multicolumn{2}{|l|}{ Echocardiographic values $(n=114)$} \\
\hline Left ventricular dysfunction $>$ mild & $5(4 \%)$ \\
\hline Right ventricular dysfunction $>$ mild & $69(59 \%)$ \\
\hline Right ventricular diameter $(\mathrm{mm})^{*}$ & $52 \pm 8$ \\
\hline Right ventricular systolic pressure (mm Hg) & $50 \pm 19$ \\
\hline Pulmonary valve peak gradient (mm Hg) & $30 \pm 21$ \\
\hline Significant pulmonary stenosis $(>50 \mathrm{~mm} \mathrm{Hg})$ & $13(11 \%)$ \\
\hline Moderate-to-severe pulmonary regurgitation & $105(89 \%)$ \\
\hline Moderate-to-severe tricuspid regurgitation & $53(45 \%)$ \\
\hline \multicolumn{2}{|l|}{ Cardiac magnetic resonance values $(n=41)$} \\
\hline Right ventricular end-diastolic volume, corrected $\left(\mathrm{mL} / \mathrm{m}^{2}\right)$ & $192 \pm 49$ \\
\hline Right ventricular ejection fraction $(\%)$ & $37 \pm 7$ \\
\hline Pulmonary regurgitant fraction $(\%)$ & $38 \pm 12$ \\
\hline \multicolumn{2}{|l|}{ Cardiopulmonary Exercise test results $(\mathrm{n}=74)$} \\
\hline $\mathrm{MVO}_{2} \max \left(\mathrm{mL} \cdot \mathrm{kg}^{-1} \cdot \min ^{-1}\right)$ & $20 \pm 6$ \\
\hline $\mathrm{MVO}_{2} \max \%$ predicted & $54 \pm 14$ \\
\hline
\end{tabular}
$64 \%$ receiving a transannular patch. At the time of reoperation, almost half of the cohort $(48 \%)$ were taking cardiac medications (furosemide, $18 \%$; digoxin, $16 \% ; \beta$-blockers, $15 \%$; warfarin, $15 \%$; amiodarone, $13 \%$; angiotensin-converting enzyme inhibitors, $9 \%$; aspirin, $10 \%$; spironolactone, $2 \%$; and angiotensin receptor blockers, $1 \%$ ).
TABLE 1. Baseline demographics $(\mathbf{n}=\mathbf{1 1 8})$

$\overline{C H F}$, Congestive heart failure; $N Y H A$, New York Heart Association; $M_{2} O_{2}$, maximum oxygen consumption. *As measured on the apical 4-chamber view (basal segment).

The indications for PVR were symptomatic severe pulmonary regurgitation $(67 \%)$, severe pulmonary regurgitation with ventricular arrhythmias $(9 \%)$, severe pulmonary regurgitation with progressive right ventricular dilatation $(12 \%)$, severe pulmonary stenosis $(9 \%)$, and others $(3 \%)$. The mean age at the time of reoperation was $36 \pm 11$ years (median, 35 years; interquartile range, $28-43$ years). Surgical intervention was performed urgently in $10 \%$ of cases. The reasons for urgent surgical intervention were endocarditis in 3 patients, sustained ventricular tachycardia in 8 patients, and right heart 
TABLE 2. Types of surgical procedures

\begin{tabular}{lc}
\hline \multicolumn{1}{c}{ Surgical procedure } & No. $(\%)$ \\
\hline Pulmonary artery arterioplasty & $87(74 \%)$ \\
RVOT aneurysmectomy & $50(42 \%)$ \\
Tricuspid valve annuloplasty & $30(25 \%)$ \\
Atrial ablation & $24(20 \%)$ \\
Ventricular ablation & $19(16 \%)$ \\
PFO/ASD closure & $25(21 \%)$ \\
Residual VSD closure & $14(12 \%)$ \\
AV repair/replacement & $4(3 \%)$ \\
Ascending aorta replacement & $4(3 \%)$ \\
MV repair/replacement & $3(3 \%)$ \\
Others & $5(4 \%)$ \\
\hline$R V O T$, Right ventricular outflow tract; $P F O$, patent foramen ovale; $A S D$, atrial septal \\
defect; $V S D$, ventricular septal defect; $A V$, aortic valve; $M V$, mitral valve.
\end{tabular}

failure with recurrent presyncopal spells in 1 patient. There were no emergency cases. Tissue valves were used in all cases: Hancock (Medtronic, Inc, Minneapolis, Minn), 84\% ( $\mathrm{n}=$ 99); Mosaic (Medtronic, Inc), 8\% $(n=9)$; homografts, 3\% $(\mathrm{n}=4)$; Carpentier-Edwards (Baxter Healthcare Corp, Santa Ana, Calif) $2 \%(n=2)$; and others, $3 \%(n=3)$. The mean size of the prosthesis was $28.9 \pm 1.6 \mathrm{~mm}$ (range, 24-33 $\mathrm{mm}$ ). Most interventions (95\%) were more complex than simple PVR alone. The most common concomitant procedures were pulmonary artery/right ventricular outflow tract (RVOT) reconstruction and tricuspid valve annuloplasty. Eleven patients had concomitant aortic or mitral valve operations (Table 2). The mean bypass time was $132 \pm 52$ minutes (median, 131 minutes; interquartile range, 93-161 minutes). Of the 61 procedures performed with an aortic crossclamp, the mean myocardial anoxic time was $30 \pm 39$ minutes (median, 11 minutes; interquartile range, 0-51 minutes).

Inotropic support was used immediately after surgical intervention in $24 \%(n=28)$ of patients and was more common in patients requiring urgent surgical intervention $(21 \%$ vs $7 \%, P=.02)$. The number of previous sternotomies $(1.5$ \pm 0.7 vs $1.2 \pm 0.41, P=.05)$, prolonged bypass time $(175 \pm$ 58 vs $119 \pm 43$ minutes, $P<.001)$ or clamp time $(45 \pm 42$ vs $26 \pm 38$ minutes, $P=.025)$, and tricuspid valve surgery (43\% vs $20 \%, P=.015$ ) were associated with the postoperative use of inotropes for more than 48 hours.

\section{Postoperative Adverse Events}

There were $3(2.5 \%)$ postoperative deaths, with no clearly preventable causative factors of death being identified. This included 2 in-hospital deaths. A 21-year-old woman who underwent elective PVR and pulmonary arterioplasty experienced cardiac arrest 24 hours after intensive care unit discharge. She underwent a sternotomy during cardiac arrest, was started on emergency cardiopulmonary bypass, and was converted to an extracorporeal membrane oxygenation circuit because of failure to wean from bypass. She had severe biventricular dysfunction and subsequently died of multiorgan failure 7 days later. She had preoperative normal biventricular

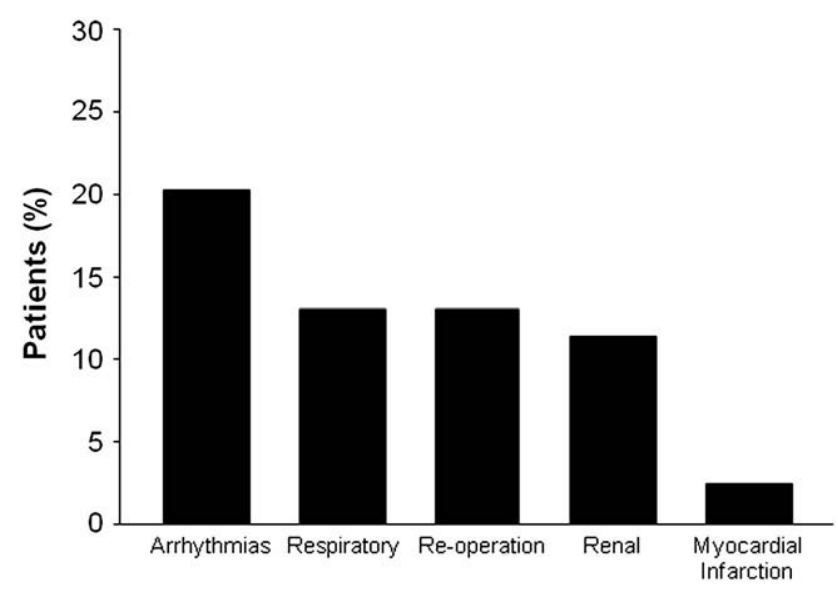

FIGURE 1. Frequency of postoperative events.

function and no history of arrhythmic events. No coronary artery injury was identified premortem or postmortem, although a large subacute hemorrhagic myocardial infarction involving the left ventricle was identified at autopsy. The second in-hospital death was in a 44-year-old man with preoperative New York Heart Association functional class III and moderate left ventricular dysfunction. He underwent elective PVR, bilateral pulmonary artery arterioplasties, and patch closure of a large residual ventricular septal defect. He was unable to be weaned off bypass because of severe biventricular dysfunction, despite subsequent fenestration of the ventricular septal defect patch. Information about intraoperative echocardiographic results is not available. There was a third death caused by intracranial hemorrhage 4 days after hospital discharge in a 43-year-old woman undergoing elective PVR who was taking chronic oral anticoagulation for prior systemic embolism. Heparin and warfarin had been commenced before hospital discharge, and then warfarin was continued in conjunction with low-molecular-weight heparin after hospital discharge. At no time, including at presentation with the cerebral bleed, had there been supratherapeutic anticoagulant levels. Information regarding patient status after discharge was not available in 4 patients.

Most patients $(60 \%)$ had no postoperative complications. The frequencies of adverse events are shown in Figure 1. The most common PAEs were arrhythmias, respiratory complications, renal dysfunction, and need for reoperation (primarily caused by bleeding). No episodes of stroke were recorded.

Postoperative arrhythmias. Postoperative arrhythmias were documented in $23(20 \%)$ patients: 19 supraventricular arrhythmias, 3 ventricular arrhythmias, and 1 case of combined supraventricular and ventricular arrhythmia. Patients who had arrhythmias when compared with patients who did not more commonly had a history of arrhythmia (74\% vs $37 \%, P=.001)$, were older at the time of reoperation (age $>45$ years: $39 \%$ vs $13 \%, P=.004$ ), and had a longer bypass time ( $155 \pm 39$ vs $126 \pm 53$ minutes, $P=.02)$. 
Respiratory complications. Respiratory complications occurred in $16(14 \%)$ patients, 4 of which were respiratory infections ( 2 with Haemophilus influenzae, 1 with Serratia species, and 1 with combined Klebsiella and Pseudomonas species) successfully treated with antibiotics. Respiratory complications were associated with more complex interventions: longer bypass time ( $179 \pm 54$ vs $125 \pm 48$ minutes, $P$ $<.001)$, increased number of previous sternotomies $(1.7 \pm$ 0.9 vs $1.2 \pm 0.4, P=.03)$, urgent procedures $(25 \%$ vs $8 \%, P=.04)$, and concomitant surgical procedures involving the tricuspid valve $(50 \%$ vs $22 \%, P=.02)$. In the subgroup of 74 patients with preoperative cardiopulmonary studies, none of the quantitative parameters (patients without vs with respiratory complications: maximum oxygen consumption, 18 vs $20 \mathrm{~mL} \cdot \mathrm{kg}^{-1} \cdot \mathrm{min}^{-1}, P=.55$; baseline oxygen saturation, $96 \%$ vs $97 \%, P=.06$; forced vital capacity, 3.2 vs $3.23 \mathrm{~L}, P=0.86$; and forced expiratory volume in 1 second, 2.5 vs $2.7 \mathrm{~L}, P=.74$ ) were associated with postoperative respiratory complications.

Reoperation. Reoperation during hospitalization was required in $16(14 \%)$, patients and the most common indication was surgical bleeding $(9 \%, \mathrm{n}=12)$. Reoperation for bleeding was not associated with prolonged hospitalization. There were no cases of cardiac tamponade. Other reasons for reoperation included debridement and rewiring of a deep wound infection $(n=1)$, initiation of extracorporeal membrane oxygenation $(\mathrm{n}=1)$, pacemaker implantation because of postoperative complete atrioventricular block $(n=1)$, and postoperative myocardial infarction caused by compression of the left anterior descendent coronary artery by one of the right outflow tract running sutures $(n=1)$. In this latter case the coronary artery was freed at the time of reoperation, and no bypass grafting was necessary.

Renal dysfunction. Renal dysfunction was documented in $15(13 \%)$ patients, 3 of whom required hemodialysis. Renal dysfunction was more common in patients undergoing urgent surgical intervention $(27 \%$ vs $8 \%, P=.05)$, patients undergoing interventions involving the tricuspid valve $(47 \%$ vs $22 \%, P=.04)$, and those who had prolonged clamp times ( $51 \pm 30$ vs $27 \pm 40$ minutes, $P=.028$ ).

Myocardial infarction. There were $4(3 \%)$ patients with myocardial infarction. Given the low atherosclerotic risk profile of our population (Table 1), the most plausible mechanism for these cardiac events were inadvertent surgical injury of the coronary arteries, especially in the presence of coronary anomalies ${ }^{18}$ which in our series was only demonstrated by means of postoperative cardiac magnetic resonance in one of the cases (anomalous coronary artery crossing RVOT).

\section{Prolonged PLOS}

The mean in-hospital length of stay was $9 \pm 8$ days (median, 7 days; interquartile range, 6-10 days). Patients with PAEs (excluding death) had a significantly longer mean PLOS (14 \pm 12 vs $7 \pm 3$ days, $P=.001)$. In 14 patients $(12 \%)$ the admission time exceeded 14 days (prolonged PLOS, as defined). Adverse postoperative events that were associated with a prolonged PLOS in a univariate analysis included respiratory complications $(50 \%$ vs $9 \%$, $P<.001)$, postoperative arrhythmia $(50 \%$ vs $16 \%, P=$ $.003)$, and acute renal failure $(43 \%$ vs $8 \%, P<.001)$. Reoperation ( $21 \%$ vs $12 \%, P=.32)$ and myocardial infarction ( $7 \%$ vs $2 \%, P=.25)$ were not associated with

TABLE 3. Univariate analysis: Predictors of prolonged postoperative length of stay

\begin{tabular}{|c|c|c|c|}
\hline Preoperative variable & Prolonged PLOS $(n=14)$ & No prolonged PLOS $(n=104)$ & $P$ value \\
\hline Sex (female) & $6(43 \%)$ & $51(49 \%)$ & .66 \\
\hline BMI $\left(\mathrm{kg} / \mathrm{m}^{2}\right)$ & $26 \pm 4$ & $26 \pm 5$ & .89 \\
\hline $\operatorname{BSA}\left(\mathrm{m}^{2}\right)$ & $1.8 \pm 0.2$ & $1.8 \pm 0.2$ & .95 \\
\hline Any CV risk factor* & $5(36 \%)$ & $36(35 \%)$ & .93 \\
\hline History of arrhythmia & $9(64 \%)$ & $43(41 \%)$ & .10 \\
\hline Admission for $\mathrm{CHF}$ & $3(21 \%)$ & $12(11 \%)$ & .29 \\
\hline Age at initial repair (y) & $11 \pm 11$ & $9 \pm 6$ & .19 \\
\hline Age at reoperation $>45 y$ & $7(50 \%)$ & $15(14 \%)$ & .001 \\
\hline No. of previous sternotomies & $1.8 \pm 0.9$ & $1.2 \pm 0.4$ & .022 \\
\hline Baseline $\mathrm{O}_{2}$ saturation (\%) & $97 \pm 2$ & $97 \pm 3$ & .83 \\
\hline Significant PS (>50 mm Hg) & $1(7 \%)$ & $12(12 \%)$ & .62 \\
\hline TR, moderate to severe & $9(64 \%)$ & $44(44 \%)$ & .14 \\
\hline QRS duration (ms) & $181 \pm 20$ & $169 \pm 25$ & .07 \\
\hline Urgent operation & $5(36 \%)$ & $7(7 \%)$ & .001 \\
\hline Tricuspid valve surgery & $6(43 \%)$ & $24(23 \%)$ & .11 \\
\hline Arrhythmia surgery & $5(36 \%)$ & $34(33 \%)$ & .82 \\
\hline Bypass time & $159 \pm 49$ & $128 \pm 52$ & .035 \\
\hline Clamp time $(\mathrm{n}=61)$ & $27 \pm 33$ & $31 \pm 40$ & .77 \\
\hline
\end{tabular}

PLOS, Postoperative length of stay; $B M I$, body mass index; $B S A$, body surface area; $C V$, cardiovascular; $C H F$, congestive heart failure; $P S$, pulmonary stenosis; $T R$, tricuspid regurgitation. *Includes smoking, diabetes, dyslipidemia, and hypertension. 
prolonged PLOS. The preoperative variables associated with PLOS in the univariate analysis are shown in Table 3 . In the multivariate model age at reoperation of greater than 45 years (odds ratio [OR], 6.1; 95\% confidence interval $[\mathrm{CI}], 1.6-23.6 ; P=.009)$, the number of previous sternotomies (OR, 3.8; 95\% CI, 1.4-10; $P=.007)$, and the need for urgent surgical intervention (OR, 5.7; 95\% CI, $1.1-27.8 ; P=.03)$ were independently associated with prolonged PLOS (Table 4). By using the 3 risk factors identified in the multivariate analysis (age $>45$ years, $\geq 2$ prior sternotomies [modified variable], and urgent surgical intervention), the frequency of prolonged PLOS (exceeding 14 days) was $3 \%, 15 \%$, and $64 \%$ in patients with 0,1 , and more than 1 risk factor, respectively.

\section{DISCUSSION}

This is the first large adult series to describe in detail the in-hospital outcomes in the growing adult population of patients with repaired TOF undergoing PVR. The mortality rate is low, and the majority of patients do not have early postoperative complications. The most common early events were arrhythmias, respiratory complications, and renal dysfunction. Although most complications will not result in long-term sequelae, they are associated with prolonged hospitalization. Patients undergoing urgent interventions, older patients, and those with multiple previous sternotomies are at the highest risk for prolonged hospitalization.

Although repeat operations for repaired TOF are becoming more common, very little information is available pertaining to the early postoperative outcomes in this group of patients. Jacquet and colleagues ${ }^{13}$ examined the results of 156 adults with congenital heart disease undergoing cardiac surgery (repair or reoperation) between 2001 and 2005 in a single institution, which included a subgroup of patients with TOF $(n=33)$. The Mayo Clinic group ${ }^{19}$ also examined the results in a group of 42 patients with repair of TOF (adult and pediatric) undergoing reoperation between 1974 and 1998. In both series there was 1 early death $(3.1 \%$ in the series of Jacquet and colleagues ${ }^{13}$ and 2\% in the series of Discigil and associates ${ }^{19}$ ), which is comparable with results in our series $(2.5 \%)$ and lower than in older (operations before 1978) published series. ${ }^{20}$

The rate of reoperation during the same admission was higher in our series compared with that seen in the previous report by Jacquet and colleagues ${ }^{13}(0 \%$ vs $14 \%)$, and exploration for bleeding was reported only in $1(2 \%)$ patient in the Mayo Clinic series ( $9 \%$ in ours). This difference in reoperation rates between studies might reflect institutional differences in the management of postoperative bleeding (6 cases of late cardiac tamponade were reported by Jacquet and colleagues ${ }^{13}$ ) and a different definition of the same outcome rather than actual different results. Nonetheless, reoperation for bleeding had no effect on PLOS in our study. When compared with postoperative complications in adults
TABLE 4. Multivariate analysis: Predictors of prolonged PLOS

\begin{tabular}{lclc}
\hline \multicolumn{1}{c}{ Preoperative factors } & Odd ratio & $\mathbf{9 5 \%} \mathbf{C I}$ & $\boldsymbol{P}$ Value \\
\hline Age at reoperation $>45 \mathrm{y}$ & 6.1 & $1.6-23.6$ & .009 \\
No. of previous sternotomies & 3.8 & $1.4-10$ & .007 \\
Urgent operation & 5.7 & $1.1-27.8$ & .033 \\
\hline
\end{tabular}

Variables entered into the multivariate model included age at reoperation of greate than 45 years, number of previous sternotomies, urgent operation, and bypass time. $P L O S$, Postoperative length of stay; $C I$, confidence interval.

undergoing surgical intervention for acquired cardiac disease, the rate of reoperation for bleeding at the surgical site is also higher in our series ( $9 \%$ vs $3.1 \%$ ). ${ }^{21}$ This difference in bleeding rate is probably related to the number of previous operations in our cohort; $58 \%$ of our patients had at least 1 previous surgical palliative procedure, and $20 \%$ had 2 or more previous sternotomies.

Arrhythmias were the most frequent complication after PVR in our cohort. In the smaller series $(n=33)$ by Jacquet and colleagues, ${ }^{13}$ similar rates of early postoperative arrhythmias $(18 \%)$ were reported. In patients with acquired heart disease, rates of postoperative arrhythmias can vary between $10 \%$ and $65 \%$ according to the definition used and the mode of monitoring. ${ }^{22}$ The propensity for arrhythmias in adults with repaired TOF has been well described, and the stress/hemodynamic changes of surgical intervention likely precipitate arrhythmias in predisposed subjects. In our series older patients with a history of arrhythmias were more prone to postoperative arrhythmias, and particular attention should be paid to this high-risk group. Whether prophylactic antiarrhythmic therapy would be beneficial is yet to be defined.

The rate of myocardial infarction $(n=4,3 \%)$ was high considering the low atherosclerotic risk profile of our cohort. Between $2 \%$ and $10 \%$ of patients with TOF have anomalous coronary arteries crossing the RVOT. Even when identified preoperatively, the anomalous arteries might pose problems at the time of intracardiac repair. ${ }^{18}$ With repeat operations and greater difficulties in the operating field caused by adhesions and distorted anatomy, these abnormal coronary arteries can be injured. One patient was found to have a left anterior descending coronary artery compromised by RVOT running sutures and required urgent reoperation. Another patient had an anomalous coronary artery crossing the RVOT that had been identified preoperatively. The underlying mechanism for myocardial ischemia could not be clarified in 2 patients. Perhaps better preoperative screening of the coronary anatomy with noninvasive imaging could guide the surgeon in the operating field to avoid some of these events.

Although we found that PAEs were relatively common, most did not result in long-term sequelae. However, the occurrence of PAEs is important because they are associated with prolonged PLOS. PLOS is being increasingly used for comparisons of surgical outcome between different centers $^{14-16}$ as a metric for the complexity of the cases and to 
help determine hospital resource consumption. In our series $12 \%$ of the patients had a postoperative hospitalization of longer than 14 days, which is clearly higher than the $5 \%$ published data from the Society of Thoracic Surgeons ${ }^{14}$ and probably in agreement with the TOF cohort from the study by Jacquet and colleagues (no data on PLOS $>14$ days but the same median and interquartile range). ${ }^{13} \mathrm{We}$ found that patients with prolonged PLOS were more likely to be older and have an increased number of previous sternotomies (more complex surgical cases). Although both of these variables have been previously shown to be determinants of prolonged PLOS, ${ }^{14}$ it is important to note that our cohort is much younger than the previous published cohorts (mean age, 36 years in our series and 65 years in the Society of Thoracic Surgeons study ${ }^{14}$ ). The rate of previous sternotomy is also significantly higher in our study cohort, and this might, in part, explain the higher rates of prolonged PLOS. In addition, urgent surgical intervention (unstable patients) was an independent predictor of PLOS. There are emerging data suggesting that an earlier indication for PVR might be important not only in improving right ventricular remodeling $^{23-26}$ but also in preventing cardiac complications, such as ventricular tachycardia and right heart failure. ${ }^{27}$ Although our results demonstrate a postoperative benefit in patients who have earlier interventions (younger patients and those undergoing elective vs urgent surgical intervention), the timing of PVR remains difficult. The need for subsequent PVR in these young patients with multiple sternotomies might become an increasingly difficult problem. A randomized clinical trial to address the timing of PVR is crucial. In addition, efforts to improve the longevity of the pulmonary valve implants to avoid reintervention remain important.

\section{Limitations}

This is a retrospective study with its inherent limitations. Because mortality in this group of patients is low, predictors of mortality could not be defined. In the future, multicenter studies might help to answer these questions. Although no predefined protocol in the postoperative management of these patients exists in our center, institutional standards of practice might influence the outcomes. Our center is a tertiary referral center, and therefore our results might not be able to be extrapolated to other centers. In addition, most interventions at our center were performed by one surgeon, which also limits the extrapolation of results to other centers. Finally, the lack of consensus in the definition of the different postoperative outcomes makes it difficult to compare results from different studies. Efforts should be made across centers to prospectively define outcomes.

\section{CONCLUSIONS}

PVR in adults with repaired TOF has a low mortality risk, and the majority of patients have uncomplicated postoperative courses. The most common early postoperative complications are arrhythmias and respiratory and renal complications. Although most early postoperative complications do not result in long-term sequelae, they are associated with prolonged hospitalization. Patients undergoing urgent interventions, older patients, and those with multiple previous sternotomies are at the highest risk for prolonged hospitalization.

\section{References}

1. Van Arsdell GS, Maharaj GS, Tom J, Rao VK, Coles JG, Freedom RM, et al. What is the optimal age for repair of tetralogy of Fallot? Circulation. 2000; 102(suppl 3):III123-9.

2. Mavroudis C, Gevitz M, Ring WS, McIntosh CL, Schwartz M. The Society of Thoracic Surgeons National Congenital Heart Surgery Database Report: analysis of the first harvest (1994-1997). Ann Thorac Surg. 1999;68:601-24.

3. Gatzoulis MA, Balaji S, Webber SA, Siu SC, Hokanson JS, Poile C, et al. Risk factors for arrhythmia and sudden cardiac death late after repair of tetralogy of Fallot: a multicentre study. Lancet. 2000;356:975-81.

4. Oechslin EN, Harrison DA, Harris L, Downar E, Webb GD, Siu SS, et al. Reoperation in adults with repair of tetralogy of Fallot: indications and outcomes. $J$ Thorac Cardiovasc Surg. 1999;118:245-51.

5. Khambadkone S, Coats L, Taylor A, Boudjemline Y, Derrick G, Tsang V, et al. Percutaneous pulmonary valve implantation in humans: results in 59 consecutive patients. Circulation. 2005;112:1189-97.

6. Lurz P, Coats L, Khambadkone S, Nordmeyer J, Boudjemline Y, Schievano S, et al. Percutaneous pulmonary valve implantation: impact of evolving technology and learning curve on clinical outcome. Circulation. 2008;117:1964-72.

7. Nashef SA, Roques F, Michel P, Gauducheau E, Lemeshow S, Salamon R. European system for cardiac operative risk evaluation (EuroSCORE). Eur J Cardiothorac Surg. 1999;16:9-13.

8. Ivanov J, Borger MA, Rao V, David TE. The Toronto Risk Score for adverse events following cardiac surgery. Can J Cardiol. 2006;22:221-7.

9. Shroyer AL, Coombs LP, Peterson ED, Eiken MC, DeLong ER, Chen A, et al. The Society of Thoracic Surgeons: 30-day operative mortality and morbidity risk models. Ann Thorac Surg. 2003;75:1856-65.

10. Vida VL, Berggren H, Brawn WJ, Daenen W, Di Carlo D, Di Donato R, et al. Risk of surgery for congenital heart disease in the adult: a multicentered European study. Ann Thorac Surg. 2007;83:161-8.

11. Berdat PA, Immer F, Pfammatter JP, Carrel T. Reoperations in adults with congenital heart disease: analysis of early outcome. Int J Cardiol. 2004;93:239-45.

12. Dore A, Glancy DL, Stone S, Menashe VD, Somerville J. Cardiac surgery for grown-up congenital heart patients: survey of 307 consecutive operations from 1991 to 1994. Am J Cardiol. 1997;80:906-13.

13. Jacquet L, Vancaenegem O, Rubay J, Laarbaui F, Goffinet C, Lovat R, et al. Intensive care outcome of adult patients operated on for congenital heart disease. Intensive Care Med. 2007;33:524-8.

14. Peterson ED, Coombs LP, Ferguson TB, Shroyer AL, DeLong ER, Grover FL, et al. Hospital variability in length of stay after coronary artery bypass surgery: results from the Society of Thoracic Surgeon's National Cardiac Database. Ann Thorac Surg. 2002;74:464-73.

15. Rosen AB, Humphries JO, Muhlbaier LH, Kiefe CI, Kresowik T, Peterson ED. Effect of clinical factors on length of stay after coronary artery bypass surgery: results of the cooperative cardiovascular project. Am Heart J. 1999;138:69-77.

16. Weintraub WS, Jones EL, Craver J, Guyton R, Cohen C. Determinants of prolonged length of hospital stay after coronary bypass surgery. Circulation. 1989; 80:276-84.

17. Reddy SL, Grayson AD, Griffiths EM, Pullan DM, Rashid A. Logistic risk model for prolonged ventilation after adult cardiac surgery. Ann Thorac Surg. 2007;84: 528-36.

18. Ozkara A, Mert M, Cetin G, Saltik L, Sarioglu T. Right ventricular outflow tract reconstruction for tetralogy of Fallot with abnormal coronary artery: experience with 35 patients. J Card Surg. 2006;21:131-6.

19. Discigil B, Dearani JA, Puga FJ, Schaff HV, Hagler DJ, Warnes CA, et al. Late pulmonary valve replacement after repair of tetralogy of Fallot. J Thorac Cardiovasc Surg. 2001;121:344-51.

20. Pome G, Rossi C, Colucci V, Passini L, Morello M, Taglieri C, et al. Late reoperations after repair of tetralogy of Fallot. Eur J Cardiothorac Surg. 1992;6: $31-5$. 
21. Karthik S, Grayson AD, McCarron EE, Pullan DM, Desmond MJ. Reexploration for bleeding after coronary artery bypass surgery: risk factors, outcomes, and the effect of time delay. Ann Thorac Surg. 2004;78:527-34.

22. Maisel WH, Rawn JD, Stevenson WG. Atrial fibrillation after cardiac surgery. Ann Intern Med. 2001;135:1061-73.

23. Therrien J, Provost Y, Merchant N, Williams W, Colman J, Webb G. Optimal timing for pulmonary valve replacement in adults after tetralogy of Fallot repair. Am J Cardiol. 2005;95:779-82.

24. Oosterhof T, Tulevski Vliegen HW II, Spijkerboer AM, Mulder BJ. Effects of volume and/or pressure overload secondary to congenital heart disease (tetralogy of Fallot or pulmonary stenosis) on right ventricular function using cardiovascular magnetic resonance and B-type natriuretic peptide levels. Am J Cardiol. 2006;97:1051-5.
25. Buechel ER, Dave HH, Kellenberger CJ, Dodge-Khatami A, Pretre R, Berger F, et al. Remodelling of the right ventricle after early pulmonary valve replacement in children with repaired tetralogy of Fallot: assessment by cardiovascular magnetic resonance. Eur Heart J. 2005;26:2721-7.

26. Frigiola A, Tsang V, Bull C, Coats L, Khambadkone S, Derrick G, et al. Biventricular response after pulmonary valve replacement for right ventricular outflow tract dysfunction: is age a predictor of outcome? Circulation. 2008;118(suppl): S182-90.

27. Knauth AL, Gauvreau K, Powell AJ, Landzberg MJ, Walsh EP, Lock JE, et al. Ventricular size and function assessed by cardiac MRI predict majo adverse clinical outcomes late after tetralogy of Fallot repair. Heart. 2008;94: 211-6.
Appendix 1. Definitions

Postoperative death

Reoperation

Postoperative arrhythmias

Respiratory complications

Renal dysfunction

Stroke

Myocardial infarction

Urgent operation

Emergency operation

Prolonged PLOS
All deaths occurring within the index hospitalization or within 30 days after the surgical procedure

Any surgical intervention performed during the same admission and after the index operation, excluding reoperation caused by defibrillator implantation in patients with inducible ventricular arrhythmias after surgical intervention A spontaneous (not induced in electrophysiologic study) sustained ( $>30$ seconds) or symptomatic arrhythmia Prolonged mechanical ventilation (defined as $>48$ hours ${ }^{17}$ ) or respiratory tract infection

An increased postoperative creatinine value with a greater than $30 \%$ decrease in creatinine clearance calculated by using the Cockroft-Gault formula below the preoperative value or requiring dialysis

A new focal neurologic deficit appearing after the surgical operation that persisted at the time of discharge, including evident deterioration in intellectual function not previously present

Persistent ST-segment elevation of greater than $1 \mathrm{~mm}$ with evolution to new Q waves postoperatively in 2 or more contiguous leads

An unplanned operation performed at or after the beginning of the next working day but with the patient kept in the hospital before the operation

An operation performed immediately on referral to the surgeon or before the beginning of the next working day A hospital admission time of $>14$ days ${ }^{14}$

PLOS, Postoperative length of stay. 